\title{
Prototype Design of Unmanned Surface Ship to Detect Illegal Fishing Using Solar Power Generation Technology
}

\author{
Yudhi Ardiyanto $^{* 1}$, Iwan Tri Sujoko ${ }^{1}$, Wicaksono Aji Wibowo ${ }^{1}$, Vendy Dwi Hendra Nugraha ${ }^{1}$, Faiz \\ Evan Saputra ${ }^{2}$ \\ ${ }^{1}$ Department of Electrical Engineering, Faculty of Engineering, Universitas Muhammadiyah Yogyakarta \\ Bantul, Daerah Istimewa Yogyakarta 55183 \\ ${ }^{2}$ Department of Mechanical Engineering, Faculty of Engineering, Universitas Muhammadiyah Yogyakarta \\ Bantul, Daerah Istimewa Yogyakarta 55183 \\ *Corresponding author, e-mail: yudhi.ardiyanto@umy.ac.id
}

\begin{abstract}
This paper describes the prototype and implementation of the unmanned surface ship to detect illegal fishing using solar power generation technology. Indonesia, one of the Southeast Asian countries, has some of the world's most productive fishing grounds. Under the leadership of President Joko Widodo, Indonesia has launched a severe crackdown on illegal fishing in its waters. The color tracking technique is the capability to take a picture, segregate a specific color, and extricate data regarding the location of that picture containing merely that color. Whilst processing the pixels in a vision, the CMUcam5 controls a counter that keeps tracking the number of consecutive pixels in the current row before being within the tracked color bounds. The current pixel is marked as a tracked pixel only when the value is higher than the noise filter value. The team has developed innovative features to complete the program. The features are double hull and propulsion design, automatic cooling system, automatic camera scanning using pixy CMUcam5 for image processing, Webcam video camera, voice command with system recognition intelligent software, fuel engine speed maximum $50 \mathrm{~km} / \mathrm{h}$, double fin, solar panel for supply battery, and computerized control. In the screen base station, we can see the situation of PTS Siluman Ship from serial communication microcontroller, serial communication image processing CMUCam 5, video webcam, GPS, and compass. All of the data from PTS Siluman Ship are sent online.
\end{abstract}

Keywords: Illegal Fishing, Surface Vessel, Pixy CMUcam5

\section{Introduction}

Abundant fish wealth in Indonesian waters is a vital potential for fishers and the people. Having a sea area of 5,200 kilometers with a width of 1,870 kilometers causes Indonesia to be called the global maritime axis. However, possessing a considerable area of waters does not evade Indonesia from naval crimes, particularly illegal fishing. In October 2015, President Joko Widodo created a task force to address illegal fishing, which reports directly to him and gives the Navy, the Maritime Security Agency and National Police full jurisdiction to detect illegal fishing.

To cope with the issue, one of the proper and efficient resolutions is through utilizing PTS SILUMAN (solar ship and microcontroller-based unmanned surface vessel of illegal fishing detection). The vessel has a monitoring and detecting system toward foreign ships with a module of pixy CMU Cam5, which can monitor continuously. The vessel can be operated with dual modes, namely autonomous and manual, using a long-distance remote control. Thus, the system is beneficial to secure and maintain the sovereignty of the Indonesian waters.

The unmanned surface vessel (USV) is mostly applied in fields of defense and security as a tool to monitor enemies and reduce the number of victims. Indeed, many researchers have investigated the USV. For instance, a study had examined the 
application areas and technologies enabling USVs to be used as a platform for marine operations. It also discussed the development of technology since the first system in 1993 through the latest development and program demonstration and described the future outlook of USV technology [1]. Another research revealed that a REMUS-100 autonomous underwater vehicle (AUV) tracked various marked sharks in the sea for a few hours. An algorithm for the vehicle was developed by the Oceanographic Systems Laboratory (OSL) to display traces of three-dimensional sharks with a high temporal and spatial resolution by utilizing information from an active transponder [2]. This study aimed to encourage the development of the USV platform used for autonomous navigation in rice fields. It employed a radio-controlled air propeller vessel altered into a USV platform. Working as the navigation system to show the location and healing angle, a GPS compass was put on the top of the USV. The USV could explore the predetermined navigation map autonomously. The GPS trajectory data obtained from the map-based navigation trial revealed that the in-system root means square (RMS) lateral error of the target path examined was less than $0.45 \mathrm{~m}$, whereas the insystem RMS heading error was 4.4 degrees or less. Meanwhile, the ultimate objective of the study was to actualize the USV platform-based paddy growth management, such as autonomous weeding and deep fertilization [3].

Another research was dealing with USV for tracking aquatic invaders. Known as extremely invasive and bottom-feeding fish, carp contaminated and dominated lakes by discharging dangerous substances. Scientists have attempted to examine carp behavior by marking them with radioemitters. The scientists attempted to discover and localize the radio-marked carp manually by utilizing a GPS and a directional antenna. A novel automated sensor system that autonomous robots will replace human effort can find and track marked carp. This paper reports our current policy and presents a modern scope algorithm to discover marked fish, active localization algorithms to localize them accurately, simulation results, theoretical analysis, and report discoveries of field tests [4]. Robotic Sensor Networks (RSNs) discovered an enhancement in environmental checking since they were able to obtain information from the obscure and inaccessible locations in the long run. This study presents the progress of building a connection of a small light-weight mechanical flatboat utilized to oversee common marked carp with radio transmitters in Lake Minnesota. Field tests were conducted in different tidal ponds to portray the architecture and design of the flatboat and illustrate the vigor of the waypoint navigation algorithms. Moreover, it presents discoveries of tests intended to localize marked fish [5].

\section{Research Method}

The design of the vessel prioritized the aerodynamic aspects of the body so that it could maneuver friskily at maximum speed. The vessel design adopted the concept of the hydro hull that could shore up heavy loads of engines, batteries, and electrical. The hull used a double hull catamaran concept, thus the vessel could maneuver stably. The design of an unmanned surface vessel (USV) can be seen in Figure 1.

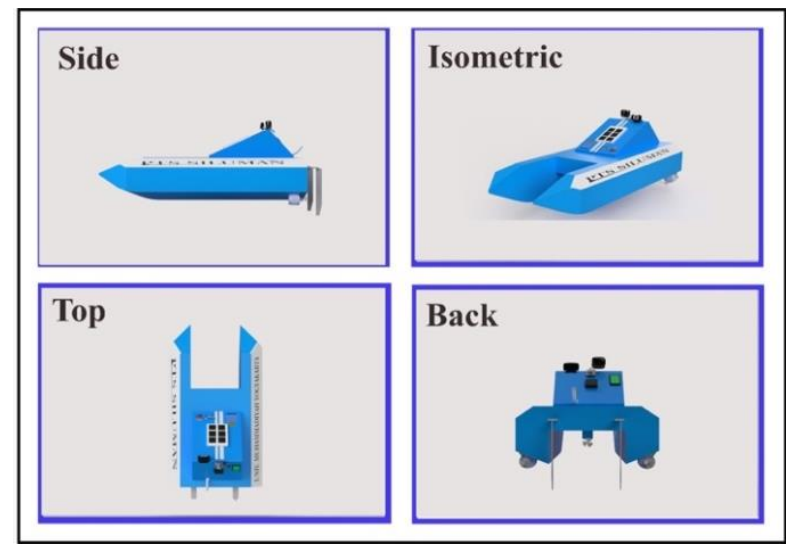

Fig. 1. The design of an unmanned surface vessel

The PTS SILUMAN worked using a camera sensor, which could lock objects with bright colors and retrieved RGB values from the traced objects. Then, the camera gave serial image information, such as a mass of $\mathrm{x}$, a mass of $\mathrm{y}$, and pixel information. When the camera sensor did not detect the object, it would perform a scanning system by moving 2 servo motors randomly to find an object. When the object was detected, the vessel's input resource used 2 batteries of Lipo 3 cell $2200 \mathrm{mAh}$ and solar panels.

The location data of the midpoint and the number of points on the camera frame were the navigation information and the detected object area. These data could be employed to control the motion of the vessel to keep objects centered on the camera lens. The microcontroller would send serial data detecting an unknown object, and then the base station would see the original image from the webcam camera. After the object was known, the 
guard gave a voice command to shoot the unknown object.

The base station could monitor the vessel as image data, real-time image data, GPS, and serial data sent online.

The system architecture of PTS SILUMAN can be seen in Figure 2, with the following requirements:

CMUCam 5 Camera: functioning to process image data with a color tracking method, which is a method of matching the colors in accordance with the object and determining the midpoint of the detected object.

Microcontroller: functioning as an electronic system controller in the vessel so that it can be operated according to the program embedded in the microcontroller.

Webcam camera: capturing image data in realtime, and being able to take pictures or videos.

GPS satellite navigation systems: designed to provide instant positions, speed, and timing information in almost any place on earth, any time and any weather so that the coordinate position of the vessel can be detected.

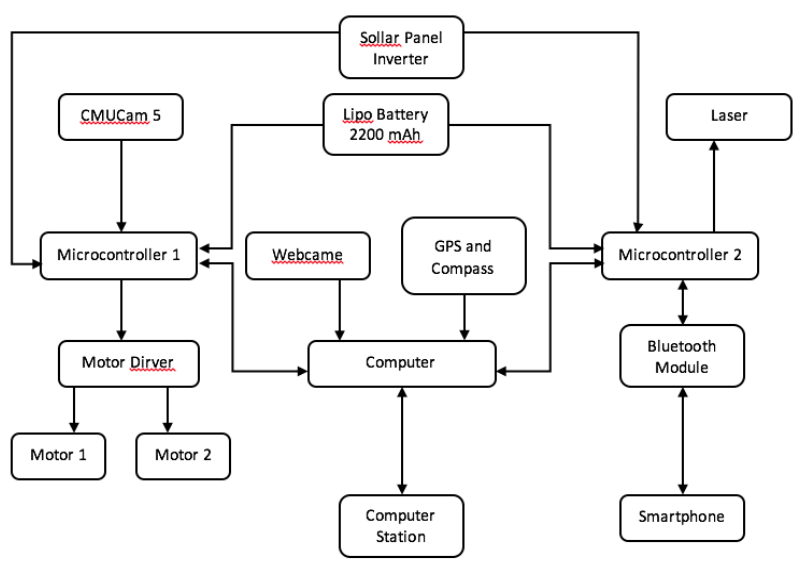

Fig. 2. The system architecture of PTS SILUMAN

SRI (System of Recognition Intelligence): It is a multifunctional software program to manage and control electronic systems of the vessel. It is a highly advanced interface user with voice input that communicates data to the user via audio. It is only limited by the program loaded into the system.

Active Cooling System: It is used as an engine cooling system that keeps working even though the engine is slow and on the surface of the water.

Voltage Source: Using lithium polymer battery of $2200 \mathrm{mAh} 2$ cell as an RC transmitter voltage source and lithium polymer battery of $2200 \mathrm{mAh} 3$ cell as an active cooling system voltage source. A solar panel was used to charge this battery.
Afterward, the next step was making a prototype of the vessel and the hull using the primary material of plywood, fiberglass, resin mixture, and catalyst. The next stage was the installation of motor and components that have been prepared, as shown in Figure 3.

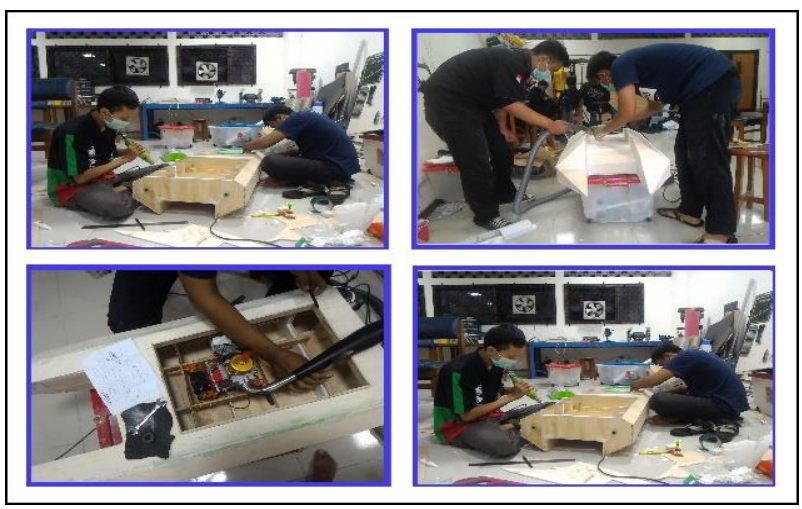

Fig. 3. Prototype making process

The overall test was performed when all components were integrated. Hence, we knew the performance of the tracking system and the distance detector object displayed on the LCD $2 \times 16$, as well as the level of accuracy distance detection reading with two conditions of light intensity, the measured value of distance detection, and the error rate through tables and diagrams. Therefore, the results of distance detection analysis by robot vision could be obtained. The next stage was a test of object detection on PixyMon, as shown in Figure 4.

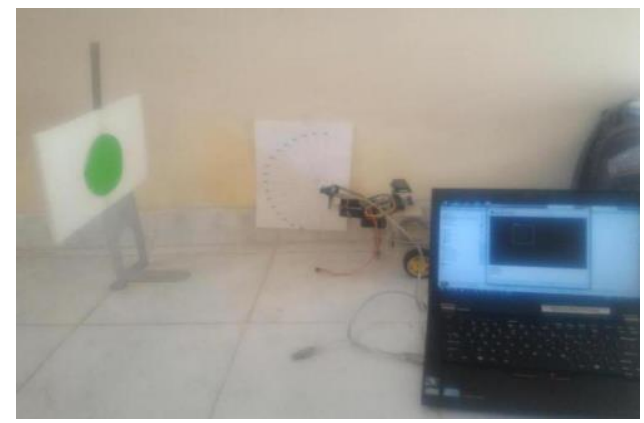

Fig. 4. Test detection object on PixyMon

\section{Results and Analysis}

\section{III.1. The PTS SILUMAN during Field Trials at Lake Campus}

Since May 2017, we have run field experiments with PTS SILUMAN in a lake near Universitas Muhammadiyah Yogyakarta (UMY), Bantul, Indonesia. The lake we used was a $20 \mathrm{~m}$ squared area with an average depth of $2 \mathrm{~m}$. As shown in Figure 5, the USV could maneuver and run well. 


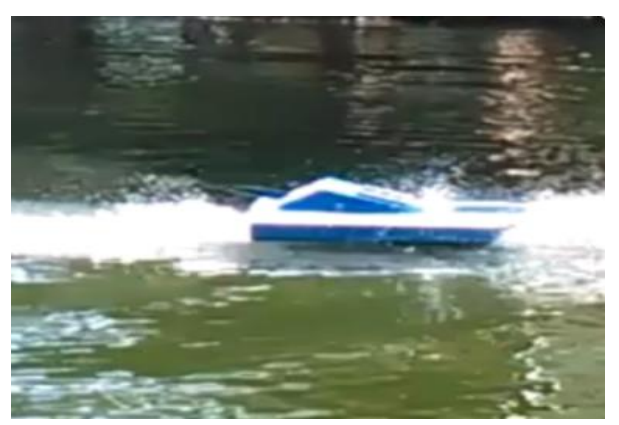

Fig. 5. PTS SILUMAN during field trials on the lake of UMY

\section{III.2. The PTS SILUMAN during field trials on the Campus Lake}

Table 1 presents the results of the distance reading of $90 \mathrm{~cm}$ objects with reading specification carried out 25 times, with the shape of a green rectangular object with size $12.7 \mathrm{~cm} \times 17.7 \mathrm{~cm}$ in a $4 \times 5 \mathrm{~m}^{2}$ room with a light intensity equal to 357 Lux. From 25 readings, a detection reading of 90 $\mathrm{cm}$ occurred 21 times, while an approximate distance of more than $90 \mathrm{~cm}$ occurred 0 times, and the estimated distance of less than $90 \mathrm{~cm}$ occurred 4 times. The average reading value above $90 \mathrm{~cm}$ was non-existent, and the estimated average reading value of less than $90 \mathrm{~cm}$ was $89 \mathrm{~cm}$. From the results of the whole data, it can be concluded that the percentage error rate at a distance reading of 90 $\mathrm{cm}$ was $1 \%$ for values less than $90 \mathrm{~cm}$, and $0 \%$ for values over $90 \mathrm{~cm}$.

Figure 6 describes the comparative analysis of phase one and phase two testing diagram above. This research concludes that the CMUCam 5 camera had a sensitivity to light intensity and contrast of object color. Therefore, we need to do color settings for tracking objects to minimize the occurring of noise that can disturb the detection of an object and cause errors at the level of distance detection accuracy.

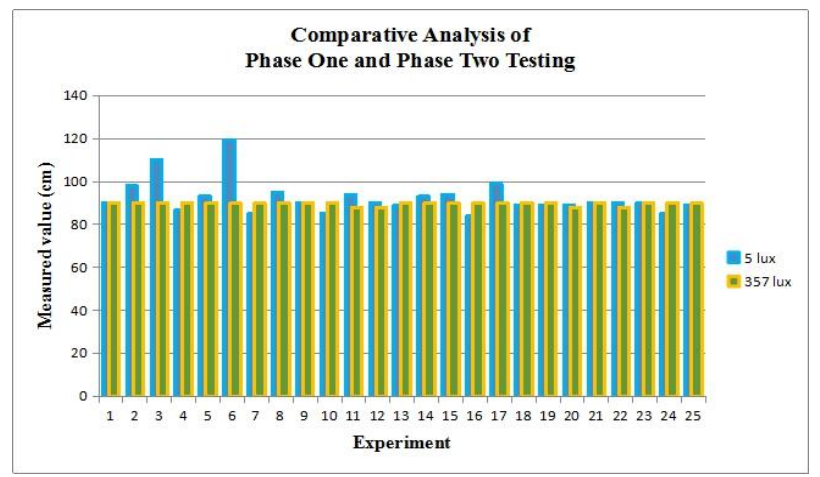

Fig. 6. Comparative analysis of phase one and phase two testing
TABLE I

Detection Test Results at 90 CM Distance With an INTENSITY OF LIGHT 357 LUX.

\begin{tabular}{|c|c|c|c|c|}
\hline No. & Read $(\mathrm{cm})$ & $90 \mathrm{~cm}$ & $>90 \mathrm{~cm}$ & $<90 \mathrm{~cm}$ \\
\hline 1 & 90 & 90 & - & - \\
\hline 2 & 90 & 90 & - & - \\
\hline 3 & 90 & 90 & - & - \\
\hline 4 & 90 & 90 & - & - \\
\hline 5 & 90 & 90 & - & - \\
\hline 6 & 90 & 90 & - & - \\
\hline 7 & 90 & 90 & - & - \\
\hline 8 & 90 & 90 & - & - \\
\hline 9 & 90 & 90 & - & - \\
\hline 10 & 90 & 90 & - & - \\
\hline 11 & 88 & - & - & 89 \\
\hline 12 & 88 & - & - & 89 \\
\hline 13 & 90 & 90 & - & - \\
\hline 14 & 90 & 90 & - & - \\
\hline 15 & 90 & 90 & - & - \\
\hline 16 & 90 & 90 & - & - \\
\hline 17 & 90 & 90 & - & - \\
\hline 18 & 90 & 90 & - & - \\
\hline 19 & 90 & 90 & - & - \\
\hline 20 & 88 & - & - & 89 \\
\hline 21 & 90 & 90 & - & - \\
\hline 22 & 88 & - & - & 89 \\
\hline 23 & 90 & 90 & - & - \\
\hline 24 & 90 & 90 & - & - \\
\hline \multirow[t]{8}{*}{25} & 90 & 90 & - & - \\
\hline & Occurred & 21 & - & 4 \\
\hline & Occurred & 84 & - & 16 \\
\hline & $(\%)$ & 1890 & - & 356 \\
\hline & Amount & 90 & - & 89 \\
\hline & Average & 0 & - & 1 \\
\hline & Difference & 0 & - & 1 \\
\hline & Error $(\%)$ & & & \\
\hline
\end{tabular}

\section{Conclusion}

The unmanned surface ship (USV) could be operated with the dual-mode operation, namely autonomous and manual, with remote control. By using wireless Bluetooth, the vessel could be operated with an android smartphone. In this paper, we compared phase one and phase two to minimize noise and have accurate object detection. Due to the limited distance of the Bluetooth to communicate, it is recommended to use wireless with a frequency of $2.4 \mathrm{GHz}$ so that the vessel can be operated with a longer distance.

\section{Acknowledgments}

This research is supported by Program Kreativitas Mahasiswa 2016 (Student Creativity Program of 2016) from The Ministry of Research and Technology for Higher Education (RISTEK-DIKTI), Republic of Indonesia. 


\section{References}

[1] Manley JE. "Unmanned surface vehicles, 15 years of development", Ocean 2008. 2008;1-4.

[2] Packard GE, Kukulya A, Austin T, Dennett M, Littlefield R, Packard G, et al., "Continuous Autonomous Tracking and Imaging of White Sharks and Basking Sharks Using a REMUS-100 AUV", Ieee/Mts Ocean. 2013;4-8.

[3] Liu Y, Noguchi N, "Development of an Unmanned Surface Vehicle for Autonomous Navigation in a Paddy Field. Eng Agric Environ Food ", [Internet]. 2015;47(3):11553-8. Available from: http://www.sciencedirect.com/science/article/pii/S1 881836615300148

[4] Tokekar P, Branson E, Vander Hook J, Isler V, "Tracking aquatic invaders: Autonomous robots for monitoring invasive fish", IEEE Robot Autom Mag. 2013;20(3):33-41.

[5] Tokekar P, Bhadauria D, Studenski A, Isler V, " A robotic system for monitoring carp in minnesota lakes", J F Robot. 2010;27(6):779-89.

\section{Authors' information}

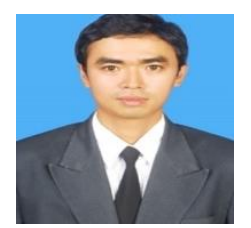

Yudhi Ardiyanto obtained his B.Sc. degree from the Department of Electrical Engineering Universitas Muhammadiyah Yogyakarta and M.Eng. degree from the Department of Electrical Engineering and Informatics Technology, Universitas Gadjah Mada, Yogyakarta, Indonesia. He is a Lecturer in the Department of Electrical Engineering, Faculty of Engineering, Universitas Muhammadiyah Yogyakarta, Indonesia. His research interests are in system, security, and computer network.

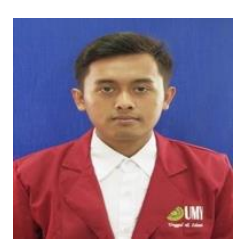

Iwan Tri Sujoko was born on 23 February 1996 in Bantul. He was a senior student in the Department of Electrical Engineering Universitas Muhammadiyah Yogyakarta at the time of this project. His research interests are in instrumentation, software engineering, and robotics.

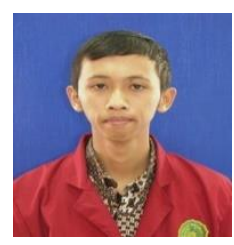

Wicaksono Aji Wibowo obtained his B.Eng. degree in the Department of Electrical Engineering Universitas Muhammadiyah Yogyakarta at the time of this project. His research interests are in instrumentation, robotics, and software development under Linux.

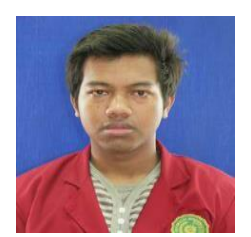

Vendy Dwi Hendra Nugraha obtained his B.Eng. degree in Department of Electrical Engineering Universitas Muhammadiyah Yogyakarta at the time of this project. His research interests are in microcontroller and robotics.

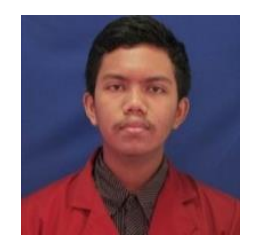

Faiz Evan Saputra was born on 5 February 1999 in Cilacap. He was a senior student in the Department of Mechanical Engineering Universitas Muhammadiyah Yogyakarta at the time of this project. His research interests are in design and manufacture. 